MAROUELLI, W.A.; LOPES, C.A.; SILVA, W.L.C. Incidência de murcha-bacteriana em tomate para processamento industrial sob irrigação por gotejamento e aspersão. Horticultura Brasileira, Brasília, v.23, n.2, p.320-323, abr-jun 2005.

\title{
Incidência de murcha-bacteriana em tomate para processamento indus- trial sob irrigação por gotejamento e aspersão
}

\author{
Waldir A. Marouelli; Carlos A. Lopes; Washington L.C. Silva \\ Embrapa Hortaliças, C. Postal 218, 70359-970 Brasília-DF; E-mail: waldir@cnph.embrapa.br
}

\begin{abstract}
RESUMO
O estudo foi realizado na Embrapa Hortaliças, Brasília (DF), com o objetivo de avaliar a incidência de murcha-bacteriana em tomateiro para processamento industrial irrigado por gotejamento e por aspersão, cultivado em solo naturalmente infestado com a raça 1, biovar I de Ralstonia solanacearum, nas condições edafoclimáticas do Cerrado brasileiro. Para gotejamento foram também avaliados os regimes hídricos com turnos de rega de 0,$5 ; 1 ; 2 ; 4$ e 8 dias. A irrigação por gotejamento favoreceu significativamente a ocorrência da doença, apresentando em média, aos 65 dias após o transplante de mudas, $42,5 \%$ de plantas com sintoma contra $5 \%$ de casos ocorridos na irrigação por aspersão. A incidência da doença no gotejamento não foi afetada ( $p>0,05)$ pelo regime hídrico adotado.
\end{abstract}

Palavras-chave: Lycopersicon esculentum, Ralstonia solanacearum, patógeno de solo, turno de rega.

\begin{abstract}
Incidence of bacterial wilt on processing tomato under drip and sprinkle irrigation

A field experiment was carried out at Embrapa Hortaliças, Brasilia, Brazil, with the objective of assessing the incidence of bacterial wilt on processing tomatoes irrigated by drip and sprinkle systems, under soil and climate conditions of the Brazilian "Cerrado". The trial was performed in a field naturally infested with race 1 , biovar I of Ralstonia solanacearum. Different irrigation frequencies $(0.5 ; 1 ; 2 ; 4$; and 8 days) were further evaluated for drip irrigation. Disease incidence was significantly higher when the crop was drip irrigated, with an average of $42.5 \%$ of wilted plants in comparison with $5.0 \%$ incidence for sprinkle irrigation, 65 days after transplanting. Frequencies of drip irrigation did not affect $(p>0.05)$ bacterial wilt incidence.
\end{abstract}

Keywords: Lycopersicon esculentum, Ralstonia solanacearum, soil borne diseases, irrigation interval.

(Recebido para publicação em 25 de agosto de 2004 e aceito em 18 de abril de 2005)

A área de tomate (Lycopersicon esculentum) para processamento industrial na região do Cerrado de Goiás e Minas Gerais foi de 13,3 mil hectares (78\% da área brasileira) no ano de 2004. A cultura é normalmente irrigada por aspersão, sendo o pivô central o sistema mais empregado na região.

Estudos realizados na Embrapa Hortaliças têm indicado que economia de água de até $30 \%$, incremento de produtividade de até $40 \%$ e melhoria da qualidade de frutos podem ser alcançados pelo uso do gotejamento e da prática da fertirrigação. Ademais, por aplicar água diretamente no solo, sem molhar a folhagem e os frutos, o gotejamento reduz a incidência de doenças da parte aérea e o apodrecimento de frutos, reduzindo substancialmente o uso de fungicidas (MAROUELLI; SILVA, 2002a, b). No ano de 2004, a área de tomateiro para processamento industrial irrigada por gotejamento foi de 1.120 ha, tendendo a aumentar expressivamente nos próximos anos, segundo previsão das indústrias de processamento. Entretanto, em observações de campo reali- zadas na Embrapa Hortaliças em 2000, verificou-se que doenças de solo, incluindo a murcha-bacteriana (MB) causada por Ralstonia solanacearum (RS), podem ser favorecidas em tomateiro irrigado por gotejamento.

É amplamente reconhecido que a MB do tomateiro está associada a solos encharcados e a altas temperaturas, sendo mais problemática no verão e em regiões de clima quente (LOPES; QUEZADO-SOARES, 1997; LOPES et al., 2000). Essa associação já havia sido observada desde o final do século XIX: na Índia, os agricultores nativos já se referiam à MB como "rasa", ou seja, "doença da umidade" (KELMAN, 1953). Um artigo clássico de Van der Meer (citado por KELMAN, 1953) comprovou que o alto teor de água no solo não só favorece a infecção inicial como também acelera o movimento da bactéria no interior dos vasos do tomateiro. Kelman (1953) constatou, em diversas partes do mundo, que a MB tem sido mais severa após períodos de alta precipitação. Entretanto, embora existam vários relatos comprovando essa as- sociação (VAUGHAN, 1944; GALLEGLY; WALKER, 1949), ainda restam algumas dúvidas a respeito do complexo solo-água-planta-patógeno. Por exemplo, em Porto Rico, a MB em tomate coincidia com períodos de alta precipitação seguido de períodos secos (NOLLA, citado por KELMAN, 1953).

Vaughn (1944) e, mais tarde, Moffet et al. (1983), trabalhando com diferentes tensões de água no solo, concluíram que, embora maior intensidade de doença ocorra em solos mais úmidos, a bactéria RS sobrevive e a doença ocorre também em solos mais secos desde que a umidade permaneça relativamente constante. Okabe (1971) por sua vez, concluiu que a sobrevivência de alguns isolados de RS foi maior sob baixa umidade do solo.

No Brasil, as primeiras informações a respeito da interação água versus $\mathrm{MB}$ se referem às afirmativas de que a $\mathrm{MB}$ raramente ocorre em batata, mesmo em solos mal drenados, desde que o plantio seja feito na época seca do ano (ALENCAR; DRUMMOND, 1944; KRAMER; AMARAL, 1944). Em estudo recente, Coelho Netto et al. (2003) 
analisaram quantitativamente esta tendência em tomate, no estado do Amazonas, onde observaram que a cv. Yoshimatsu apresentou mais de $50 \%$ de mortalidade em várzeas inundadas, comparados com $22,5 \%$ de mortalidade em terra firme. Nenhum trabalho, entretanto, foi conduzido com a finalidade de relacionar incidência da doença ao sistema de irrigação utilizado.

Nos últimos cinco anos, a MB não tem sido problema limitante à cultura do tomateiro para processamento industrial na região do Cerrado do Brasil, onde os plantios coincidem com o período seco e frio do ano (abril a junho) e a irrigação é realizada por aspersão. Ressalta-se o fato de que estes cultivos são muitas vezes realizados em áreas novas ou após a rotação com gramíneas, principalmente pastagens, o que reduz os riscos de infecção pela garantia de baixo nível de inóculo inicial.

Em virtude do potencial aumento da área de tomateiro para processamento industrial irrigado por gotejamento no Brasil, objetivou-se neste trabalho avaliar a incidência de murcha-bacteriana em tomateiro irrigado por gotejamento e por aspersão, assim como verificar o efeito da frequiência de irrigação por gotejamento na ocorrência da doença, nas condições edafoclimáticas da região do Cerrado.

\section{MATERIAL E MÉTODOS}

O experimento foi conduzido no campo experimental da Embrapa Hortaliças, em Brasília, em latossolo vermelho-escuro distrófico, fase cerrado e textura argilosa, $150 \mathrm{~mm} \mathrm{~m}^{-1}$ de capacidade de retenção de água, em uma área naturalmente infestada por Ralstonia solanacearum, raça 1 , biovar I.

Os tratamentos foram constituídos de irrigação por gotejamento, com turnos de rega de 0,$5 ; 1 ; 2 ; 4$ e 8 dias, e por aspersão como controle. No tratamento controle foi adotado esquema de manejo da irrigação recomendado por Marouelli e Silva (2000), capaz de maximizar o rendimento da cultura.

O transplante das mudas do híbrido AP533 foi realizado na primeira semana de junho de 2001, no espaçamento de $30 \times 120 \mathrm{~cm}$, em solo previamente irrigado à capacidade de campo na camada até $40 \mathrm{~cm}$. A parcela experimental foi de 28,8 $\mathrm{m}^{2}$ (4 linhas de 6,0 m).

A adubação, por hectare, foi realizada com $200 \mathrm{~kg}$ de N, $300 \mathrm{~kg}$ de $\mathrm{K}_{2} \mathrm{O}$, $600 \mathrm{~kg}$ de $\mathrm{P}_{2} \mathrm{O}_{5}, 160 \mathrm{~kg}$ de $\mathrm{Ca}, 40 \mathrm{~kg}$ de $\mathrm{Mg}, 65 \mathrm{~kg}$ de $\mathrm{Zn}$ e $2 \mathrm{~kg}$ de B, tendo sido utilizadas as seguintes fontes: uréia, nitrato de potássio e de cálcio, cloreto de potássio, superfosfato simples, cal hidratada, cloreto de cálcio, sulfato de magnésio e de zinco e boráx. Nos tratamentos por gotejamento foi realizada fertirrigação, com esquema de parcelamento segundo Marouelli e Silva (2002b). No tratamento por aspersão, $35 \%$ do N, $60 \%$ do $\mathrm{K}$ e $70 \%$ do Ca foram aplicados em pré-plantio e o restante em cobertura aos 25 dias e 50 dias após o transplante, sendo o restante dos nutrientes fornecido em pré-plantio.

Nos tratamentos por gotejamento, a irrigação foi realizada com uma linha de gotejadores, espaçados de $30 \mathrm{~cm}$ e com vazão de $1,2 \mathrm{~L} \mathrm{~h}^{-1}$, por linha de plantas. $\mathrm{Na}$ aspersão utilizaram-se microaspersores com intensidade de aplicação de $25 \mathrm{~mm} \mathrm{~h}^{-1}$.

Visando garantir um pegamento uniforme de mudas, as irrigações, nos primeiros cinco dias após o transplante, foram realizadas diariamente em todos os tratamentos. A partir desse período, os turnos de rega nos tratamentos por gotejamento foram diferenciados. No tratamento por aspersão, as irrigações passaram a ser realizadas a cada 5 a 7 dias, intervalo médio recomendado para as condições edafoclimáticas do Cerrado (MAROUELLI et al., 2000).

A lâmina de água aplicada por irrigação foi computada a partir da evaporação do tanque Classe A e coeficientes de cultura reportados por Marouelli e Silva (2002b), para gotejamento, e por Marouelli e Silva (2000), para aspersão. Ajustes nas lâminas, especialmente nos tratamentos por gotejamento com turnos de rega de 4 e 8 dias, foram realizados a partir da avaliação da tensão de água no solo (MAROUELLI; SILVA, 2002b).

O monitoramento da água no solo, nos tratamentos por gotejamento com turnos de rega entre 0,25 e 4 dias, foi realizado por tensiômetros instalados em cada parcela experimental nas profundidades de 10; 20 e 40 cm e distan- ciados a $10 \mathrm{~cm}$ da planta e do emissor (MAROUELLI; SILVA, 2002b). Nos tratamentos por gotejamento com turno de rega de 8 dias e por aspersão, a tensão foi estimada indiretamente a partir da avaliação da umidade do solo pelo método padrão das pesagens.

A incidência de MB foi avaliada a cada 10 dias por meio de contagem de plantas com sintomas da doença em cada parcela. Após as contagens, as plantas doentes foram arrancadas e retiradas da área experimental. Foram realizadas cinco contagens entre os 25 (início da floração) e 65 dias (início da maturação) após o transplante das mudas.

O delineamento experimental foi em blocos casualizados, no esquema de parcelas subdivididas (seis tratamentos versus cinco épocas de avaliação da doença), com quatro repetições. Os dados referentes à ocorrência de $\mathrm{MB}$ nos tratamentos irrigados por gotejamento, em cada época de avaliação, foram submetidos à análise de variância. Para confrontar as médias do tratamento controle, irrigado por aspersão, contra as médias dos tratamentos por gotejamento foi empregado o teste " $t$ " de comparação múltipla de Dunnett. Considerando a alta variabilidade da infestação natural da RS em condições de campo, foi considerado $\mathrm{p}=0,10$ como limite de significância para as análises estatísticas realizadas.

\section{RESULTADOS E DISCUSSÃO}

As variáveis relativas ao manejo da irrigação, representadas pela lâmina líquida de água total aplicada e valores médios de tensão e fração de água disponível no solo, antes de cada irrigação, nos tratamentos por gotejamento e aspersão, são apresentadas na Tabela 1 .

Maior quantidade de água foi aplicada ao tomateiro irrigado por aspersão, tendo as lâminas sido reduzidas quanto maior o intervalo de rega nos tratamentos por gotejamento. Por outro lado, condições de maior umidade no solo ocorreram nos tratamentos por gotejamento em regime de mais alta frequiência. O teor de água no solo antes de cada irrigação no tratamento por aspersão foi a menor dentre todos os tratamentos. Maior tensão de água no solo 
Tabela 1. Lâmina total líquida de água aplicada, tensão e porcentagem média de água disponível no solo, logo antes das irrigações, nos tratamentos por gotejamento e por aspersão, durante os 65 dias de condução do experimento. Brasília, Embrapa Hortaliças, 2002.

\begin{tabular}{|c|c|c|c|}
\hline Tratamento & Lâmina $(\mathrm{mm})^{1}$ & Tensão $(\mathrm{kPa})^{2}$ & Água disponível $(\%)^{2,3}$ \\
\hline Gotejo 0,5 dia & 218 & 7 & 100 \\
\hline Gotejo 1 dia & 218 & 10 & 90 \\
\hline Gotejo 2 dias & 204 & 17 & 75 \\
\hline Gotejo 4 dias & 190 & 38 & 40 \\
\hline Gotejo 8 dias & 178 & 73 & 25 \\
\hline Aspersão & 232 & 98 & 20 \\
\hline
\end{tabular}

${ }^{1}$ Incluindo irrigação de pré-plantio. Adicionalmente ocorreram chuvas que totalizaram 3,4 $\mathrm{mm} ;{ }^{2}$ Avaliado a $50 \%$ da profundidade efetiva do sistema radicular do tomateiro; ${ }^{3}$ Considerou-se $10 \mathrm{kPa}$ como a tensão associada à capacidade de campo e $1.500 \mathrm{kPa}$ para ponto de murcha.

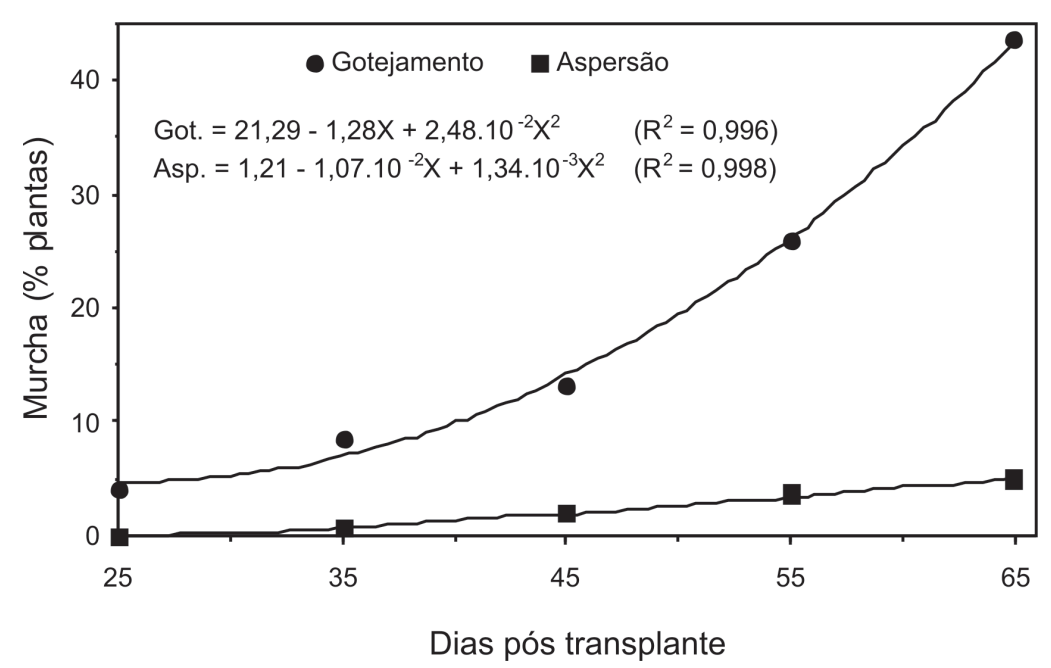

Figura 1. Porcentagem acumulada de plantas de tomateiro com murcha-bacteriana, entre 25 e 65 dias após o transplante, para irrigação por gotejamento (média dos tratamentos) e por aspersão. Brasília, Embrapa Hortaliças, 2002.

em plantas irrigadas por aspersão, comparativamente aos tratamentos por gotejamento, mesmo tendo sido maior a lâmina total líquida de água aplicada na aspersão, foi também observada por Marouelli e Silva (2002a) e Marouelli et al. (2003). Isso se deve, provavelmente, à maior taxa de evaporação e de transpiração, nos primeiros dias após a irrigação por aspersão, resultante do fato da água ser aplicada sobre toda a superfície do solo (100\% de molhamento superficial do solo e das plantas) e do maior desenvolvimento lateral das raízes do tomateiro.

Pelo teste de Dunnett, a incidência de MB em plantas irrigadas por gotejamento, para todos os regimes hídricos e épocas de avaliação da doença entre 45 e 65 dias, foi significativa- mente $(p<0,10)$ mais alta do que em plantas irrigadas por aspersão. Para as épocas de avaliação aos 25 e 35 dias não verificou-se diferenças significativas $(p>0,10)$ entre os tratamentos por gotejamento com turnos de rega de $4 \mathrm{e}$ 8 dias e o tratamento controle, mas houve para os demais turnos de rega. Tal fato indica que a maior variabilidade do teor de água no solo entre irrigação, nos tratamentos por gotejamento com freqüência de 4 e 8 dias, favoreceu uma maior multiplicação e infecção inicial das plantas, conforme relatado por Moffel et al. (1983).

Pela análise de variância realizada, não foi observada diferença significativa $(p>0,10)$ para a incidência de $M B$, nas cinco épocas de avaliação da doença, em função dos diferentes regimes hídricos adotados nos tratamentos por gotejamento, e para a interação entre incidência de MB e época de avaliação. Com isso, foi possível estabelecer a evolução de MB considerando-se os valores médios temporais de incidência nos tratamentos irrigados por gotejamento e os valores de incidência do tratamento por aspersão (Figura 1). Para a época de avaliação aos 65 dias após o transplante, a incidência de 5\% de plantas murchas na irrigação por aspersão foi estatisticamente inferior $(\mathrm{p}<0,05)$ àquela observada nos tratamentos por gotejamento (média de 42,5\%).

A razão para a maior ocorrência de MB em tomateiro irrigado por gotejamento deve-se, provavelmente, ao fato de a água ser aplicada de forma localizada. Neste sistema, há a formação de um bulbo saturado próximo ao gotejador durante a irrigação e mesmo algumas horas depois do término, o que favorece o processo infeccioso em torno do sistema radicular. Na aspersão, por outro lado, a água é aplicada sobre toda a superfície do solo, sendo rapidamente redistribuída no perfil, sem causar saturação do mesmo. Além disso, a maior variação de umidade na camada mais superficial do solo entre as irrigações no tratamento por aspersão, comparativamente aos tratamentos por gotejamento (Tabela 1), também pode ter contribuído para a menor sobrevivência e, conseqüente, pequena infecção das plantas pela bactéria RS (MOFFETT et al., 1983). McCarter et al. (1969), ao estudarem a distribuição vertical de RS em vários tipos de solo, verificaram que a população bacteriana na camada superficial do solo (0 a $15 \mathrm{~cm}$ ) foi muito menor que na camada mais profunda (15 a $30 \mathrm{~cm}$ ), o que foi atribuído à maior variabilidade da umidade do solo na camada superficial. Também Okabe (1971) e Graham e Lloyd (1979) mostraram que o patógeno apresenta menor capacidade de sobrevivência na camada mais superficial do solo, e que bolsões infestados a maiores profundidades favorecem a sobrevivência da bactéria por maior tempo.

Esperava-se que os tratamentos por gotejamento irrigados em regime de menor frequiência favorecessem menor incidência de $\mathrm{MB}$, o que não foi observado de forma significativa. Uma pos- 
sível explicação para esse fato é o de que, mesmo sob irrigações mais espaçadas, um bulbo com alta umidade é conservado na rizosfera da planta durante tempo suficiente para favorecer a multiplicação e a infecção das plantas pela bactéria RS.

Os resultados obtidos no presente estudo servem de alerta para produtores que planejam substituir sistemas de irrigação por aspersão pelo sistema por gotejamento. Para regiões e épocas de plantio sujeitos à temperaturas acima daquelas observadas no presente estudo (temperatura do ar: média de $21,1^{\circ} \mathrm{C}$; máxima de $28,2^{\circ} \mathrm{C}$ ), os riscos da ocorrência de MB poderão ser ainda maiores, segundo Lopes et al. (2000).

\section{LITERATURA CITADA}

ALENCAR, J; DRUMMOND, O.A. Notas sobre a murcha bacteriana da batatinha e do tomateiro (Bacterium solanacearum E.F Smith). Revista Ceres, Viçosa, v.5, p.178-225, 1944.

COELHO NETTO, R.A.; PEREIRA, B.G.; NODA, H.; BOHER, B. Caracterização de isolados de Ralstonia solanacearum obtidos de tomateiros em várzea e em terra firme, no Estado do Amazonas. Fitopatologia Brasileira, Fortaleza, 2003 (no prelo).
GALLEGLY JR., M.E.; WALKER, J.C. Relation of environmental factors to bacterial wilt of tomato. Phytopathology, v.39, p.936-946, 1949.

GRAHAM, J.; LLOYD, A.B. Survival of potato strain (race 3) of Pseudomonas solanacearum in the deeper soil layers. Aust. J. Agric. Res., v.30, p.489-496, 1979.

KELMAN, A. The bacterial wilt caused by Pseudomonas solanacearum: a literature review and bibliography. Tech. Bull. No 99, North Carolina Agricultural Experiment Station. 1953.

KRAMER, M.; AMARAL, J.F. Identificação da "murcha bacteriana" presente em culturas de batatinha do Estado de São Paulo. O Biológico, São Paulo, v.10, p.199-207, 1944.

LOPES, C.A.; QUEZADO-SOARES, A.M. Doenças bacterianas das hortaliças: diagnose e controle. Embrapa-SPI, Brasília. 1997. 70 p.

LOPES, C.A.; SANTOS, J.R.; ÁVILA, A.C.; BEZERRA, I.C.; CHARCHAR, J.M.; QUEZADO-DUVAL, A.M. Doenças: identificação e controle. In: SILVA, J.B.C.; GIORDANO, L.B., (Ed.) Tomate para processamento industrial. Brasília: Embrapa Comunicação para Transferência de Tecnologia: Embrapa Hortaliças, 2000. p.88-111.

MAROUELLI, W.A.; SANT'ANA, R.R.; SILVA, W.L.C.; MORETTI, C.L.; VILELA, N.J. Avaliação técnica e econômica do espaçamento de gotejadores em tomateiro para processamento cultivado em fileiras simples e duplas. Horticultura Brasileira, v.21, p.202-206, 2003.

MAROUELLI, W.A.; SILVA, W.L. Irrigação. In: SILVA, J.B.C.; GIORDANO, L.B., ed. Tomate para processamento industrial. Brasília: Embrapa, 2000. p.60-71.
MAROUELLI, W.A.; SILVA, W.L.C. Profundidade de instalação da linha de gotejadores em tomateiro para processamento industrial. Horticultura Brasileira, Brasília, v.20, p.206-210, 2002a.

MAROUELLI, W.A.; SILVA, W.L.C. Tomateiro para processamento industrial: irrigação e fertirrigação por gotejamento. Brasília: Embrapa Hortaliças, 2002b. 32 p. (Embrapa Hortaliças. Circular Técnica, 30).

MAROUELLI, W.A.; SILVA, W.L.C.; SILVA, H.R.; VILELA, N.J. Eficiência econômica do manejo racional da irrigação em tomateiro para processamento industrial. Horticultura Brasileira, Brasília, v.18, p.238-243, 2000.

McCARTER, S.M.; DUKES, P.D.; JAWORSKI, C.A. Vertical distribution of Pseudomonas solanacearum in several soils. Phytopathology, v.59, p.1675-1677, 1969.

MOFFET, M.L.; GILES, J.E.; WOOD, B.A. Survival of Pseudomonas solanacearum biovars 2 and 3 in soil: effect of moisture and soil type. Soil Biology and Biochemistry, v.15, p.587-592, 1983.

OKABE, N. Population changes of Pseudomonas solanacearum and soil microrganisms in artificially infested natural soils. Review Plant Prot. Res., v.4, p.105-108, 1971.

VAUGHAN, E.K. Bacterial wilt of tomato caused by Phytomonas solanacearum. Phytopathology, v.34, p.443-458, 1944. 